\title{
Methodological approaches to the assessment of the cluster potential of the economy of a region
}

\author{
Mikhail M. Guzev \\ Volzhskiy branch \\ Volgograd State University \\ Chair of Economic Theory and Management \\ Volzhskiy, Russia \\ guzev@vgi.volsu.ru
}

\author{
Elena Yu. Dubovikova \\ Volzhskiy branch \\ Volgograd State University \\ Department of scientific and international activity \\ Volzhskiy, Russia \\ dubovikovae@rambler.ru
}

\author{
Natalia A. Mishura \\ Volzhskiy branch \\ Volgograd State University \\ Department of scientific and international activity \\ Volzhskiy, Russia \\ mis.nata-volga@yandex.ru
}

\begin{abstract}
The paper is devoted to the development of methodological approaches to the identification of regional clusters and to the determination of the cluster potential of a territory. It was proved that the specification of the cluster potential of the economy of a region can be carried out on the basis of the system of qualitative criteria (cluster characteristics) and qualitative parameters in the potential cluster group. The mathematical description of threshold values, the total of which allows making the conclusion about the transformation of quantitative measurements into qualitative ones and into the possibilities of cluster changes was made. The main qualitative parameter of a potential cluster is the innovation focus of its participants which is taken into account. The analysis of the importance of innovation of a cluster group when using the "Coefficient of a localized innovation" for calculation is suggested. The elements for the mechanism of the encouragement of the innovative cluster initiative are as follows: competition, market institutes, cluster policy, state and private partnership.
\end{abstract}

Keywords - cluster potential, territorial localization, cluster group, operational approach, factor approach, quantitative parameters, qualitative parameters, innovation focus, mechanism of realization of cluster potential

\section{INTRODUCTION}

In the Russian economy as a reflection of world trends, the process of cluster formation at national and regional levels is observed. In the developed countries according to expert assessments more than $50 \%$ of their economies are involved into cluster formation what is determined by the increase of competitiveness of economic actors being part of clusters.
The theoretical basis of the clusters study are the scientific papers of A. Weber, G. Myrdal, A. Marshall, E. Robinson, J. Thünen and such national scientists M. Bandman, A. Granberg, N. Kolossovskiy, N. Nekrasov and others whose papers are devoted to the problems of territories and placement of local industrial plants in them. The papers of $\mathrm{M}$. Porter who is the founder of the modern cluster approach in the economic research are also extremely important. Nevertheless despite the growing number of the publications in cluster problem the lack of research devoted to the methodical and methodological problems of cluster identification and specification of cluster potential of the regional economy, determination of basic principles, tendencies and strategies of cluster creation, development of the peculiarities of the mechanism of forming and development of regional clusters in Russia is observed.

The goal of the research consists in the development of methodological approaches to the identification of regional clusters on the basis of the analysis of the complex of quantitative and qualitative basic characteristics of cluster groups.

The analysis of production factors and arrangement of the cluster attributes allows determining as the main qualitative characteristic of a potential cluster its innovation focus a high density of technical and technological relations of economic agents, suppliers, consumers and contractors in the local territory, competition which constantly encourages innovations. 
The goal of the research determines the setting of the tasks: to identify of a cluster by means of the analysis of its basic qualitative attributes, to specify basic evaluative indicators of a potential cluster; to reveal the content of the dominating characteristic, its innovation focus; to perform the mathematical description of threshold values, the complex of which allows drawing the conclusion about the transformation of quantitative changes into qualitative ones and about the possibility of a cluster appearance; to calculate the coefficient of a localized innovation; to specify the mechanism of the encouragement of a cluster initiative.

\section{MATERIALS AND METHODS}

An operational approach to the specification of clusters arranging its characteristics is used. The methodology of a cluster analysis including the specification of a complex of qualitative attributes and quantitative characteristics is suggested. The factor approach was realized. For the present moment the most perspective method of the analysis is the six factor approach including human, technical, natural, institutional, organizational and informational factors [1]. This type of methodology expands beyond and widens narrow frames of the classical approach, avoids one sided approach and outstanding attention to some factors what enlarges the opportunities of research of modern real processes in the economy. It is spoken about in particular about the process of the formation and functioning of regional clusters the dominant of which are synergetic innovation advantages. The methodic approaches of the analysis of a complicated economic system are used.

\section{RESULTS AND DISCUSSION}

Within the goal of the implementation of the regional strategy directed on the competitiveness growth of the regional economy the authorities of different levels of administration show the interest in the development of clusters. Together with that the lack of adequate operational approaches to the identification and specification of the mechanisms of cluster development prevents the transition of the country to an innovation model of regional economy. It was proved that a regional cluster as an economic category reflects competitive and at the same time cooperative relations between independent economic agents concentrated in a geographically limited space for the provision of a high competitiveness at international, national, regional levels and in the enterprises when producing innovation goods and services. Consequently the start of the cluster formation process can be used as a tool of the growth of regional competitiveness by means of the combination and implementation of interests of all economic agents in a cluster as a factor of innovation and business development in a region.

The cluster formation becomes an objective process taking place in various environments the result of which are the economic agents who create groups under the influence of a subjective factor and in this case here the production of goods and services, high productivity and competitiveness, innovation character and complementarity of companies and organizations are meant.
In many European countries the cluster approach is one of conceptual bases of government regulation in the economy as the competitiveness of the country in the world market is determined not by the competitiveness of legal entities but by the competitiveness of clusters uniting the firms of various industries.

The evaluation of a cluster potential of a regional economy on the basis of the cluster analysis which includes the specification of the complex of qualitative attributes and quantitative parameters of clusters will provide the best account of economic interests of all the participants of market relations.

The identification of clusters from their qualitative characteristic includes the isolation of the following attributes in a local area.

The first attribute is the capacity of self organization. The clusters are created on the basis of free entrance and exit, on the independence of economic agents, on the aspiration of everyone to realize his or her interest in a harmonious way, on the cooperation of various enterprises, organizations and establishments of industries of national economy and spheres of activity. The cluster is a self organizing social and economic space of a free development of all and everyone.

In this respect D.P. Flolov and D.V. Grushevskiy notice that the "cluster formation is an evolutionary process whose artificial acceleration is inacceptable. The clusters organically combine the characteristics of stochastic and deterministic systems. That's why all the attempts to form them from "the top" under the slogan "All go a cluster!" are inevitably devoted to destruction" [2].

The second attribute is a territorial localization. The cluster is a complex of closely interrelated localized independent enterprises and organizations, "geographically limited group of companies, suppliers, service providers and associated institutes of a corresponding sphere related by the interactions of various types" [3].

The third attribute is the capability of efficient use of internal resources. It is provided by the net form of the economic agglomeration and the advantages of cooperation, by the economizing on transaction costs, close and stable relations between all the cluster subjects and at the same time the openness of the system. A cluster is neither a holding, nor an association of enterprises in the region, nor a technopark, nor a business incubator, moreover nor a territorial and production complex or even a scientific and production association. The cluster has three levels of organization: "nucleus" of cluster which is presented by large companies, organizations supplying the "nucleus" with resources; net of suppliers presented by small and medium sized firms. The net consists of producers who are usually suppliers, consumers (buyers), intermediaries, servicing organizations, knowledge generators and specific means of electronic calculations.

Here comes the definition: "cluster is an organization of the activity of territorially localized complex of companies working in the net form, joined by relations having both formal and non formal character, subject to a common goal which in the result of a close interaction in the whole 
technological chain efficiently and it creates competitive advantages in this territory» [4]. Such a net organization is focused on the use first of all, of internal resources.

The fourth attribute is an internal competition. The competition is a key characteristic of the cluster and the clusters imply its presence. The firms making part of the cluster study and analyze the production capacities of their colleagues. Every organization participating in the cluster pursue the competition between the firms in the cluster by means of creating a specific mechanism of the interaction of its participants what in the market conditions inevitably leads to the innovation development, to the dynamic character of interests, freedom of the entrance into the cluster and of the exit from it. Thus the enterprises get the opportunity of paying more attention to their specialization and precisely to focus on the plants which determine competitive advantages of the production. The remaining links of the production change can and must be given to the enterprises which focus on the performance of the processes typical of them.

The fifth attribute is the competitiveness. The growth of the competitiveness is achieved first of all by the advantages of cooperation and vertical technical integration, increase of the accessibility of new technologies, reduction of costs and dynamic character of net environment of independent agents of the clusters. Beyond the clusters it is more complicated and sometimes it is impossible to get access to necessary resources for the economic agents. A low competitiveness of the economic agglomeration does not allow identifying it as a cluster or having the properties of a cluster. The advantage of the work in a cluster of enterprises and organizations, increase of their profitability and the reduction of expenses and also the increase of competitiveness is a dominating motive in the entrepreneurial activity. The competition is a universal condition at the same time of the achievement of all these goals and the solution of corresponding tasks. The competition forces the economic agents to make various mutually profitable agreements, to take into account not only its competitive abilities but also and the competitiveness of all interrelated enterprises and organizations (cluster participants). The competition is an element of the mechanism of the self organization of a cluster. The absence of the competition, underassessment of its role leads to the delay in the process of the cluster creation.

The sixth attribute is the basic, dominant one and it is the innovation focus. A high specialization, cooperation and integration, density of technical and technological relations of the cluster subjects (suppliers, consumers, contractors with the conservation of the competition in the local area) inevitably encourages innovations, their quick introduction, experience exchange.

The cluster organization of the economy allows reacting more quickly and adequately on the consumer demands by means of the inter company cooperation, allows reducing the expenses for R\&D and allows getting access to new knowledge and technologies. Besides "clusters as a rule are formed in the places where the "groundbreaking" advancement in technology and equipment of production and the consequent exit to new «market niches» exists [5].
The clusters with techoparks and business incubators should not be mixed up. Although the latter have innovative character the firms in them do not necessarily interact with one another closely and mutually profitable. It is no coincidence that in the process of the identification of clusters in European countries the main criteria became the study of the closeness of vertical and horizontal relations between enterprises, academic, research, regional entrepreneurial and public organizations. The «Maxima method» or «M method» was used which classifies the sector (industry) of economy in compliance with "constantly existing dependent relations between suppliers and buyers in one economic cluster" [6]. In the end a number of interesting results was obtained. Thus the industrial regions, spheres of technological competitiveness were specified.

The innovation aspect in clusters is reinforced by the peculiarity of their functioning: the use of ways of the efficiency increase of the authors of innovative ideas, adaptability and sensibility of the ideas implementers, reactivity of the agents supplying the innovation process with the resources.

Let us study more precisely the reasons of the formation of innovation advantages in a cluster as both in theory and in practice there exists in our opinion the underestimation of the innovation constituent in their organization.

In the scientific papers two main fundamental reasons why the enterprises interested in the innovative development are concentrated in clusters are studied. First of all new knowledge has a considerable personified part [7] and it is efficiently spread by means of a personal contact. «The point is that as $\mathrm{P}$. Desrochers mentions the most important knowledge in any technology intensive information, it is not the information about standardized actions and these are not scientific publications. It is also not the information that you can get by means of a quantitative marketing analysis (analysis of secondary information and statistical data) and even not the information obtained during the questioning and focus groups. What is really important in the business is the newest knowledge, information about the latest changes, experience of people who got it through the practice» [8]. The regular personal contacts imply that the interacting agents are located close to one another. An obvious consequence for that is an uneven distribution of the innovative activity in the space. Secondly, the innovation activity implies the coordinated work of numerous organizations: detail suppliers, producers, sellers, consumers, financial organizations and so on. «For the implementation of an innovation, the partners consumers and partners suppliers are needed. And the more radical (and very often more valuable) an innovation is, the more considerable, extensive other players should be involved, especially consumers» [9]. Even venture entrepreneurs invest money as a rule into companies which are located next to them. The necessity of the geographic localization of many related organizations for the implementation of the innovation process is proved in the practice [10]. 
The presence in a cluster of numerous companies of the same or related types of activity and also the consumers of their production increases the requirements for demand and encourages the competitive fight. M. Porter specifically emphasizes the internal competition (in comparison with the distant competition) as a factor encouraging the innovation activity of firms.

Thus for the encouragement of full innovation activity, the enterprises should be placed and function within the cluster. The cluster here means interacting organizations located geographically and joined by common industries which constantly improve their competitive advantages (Figure 1) [11].

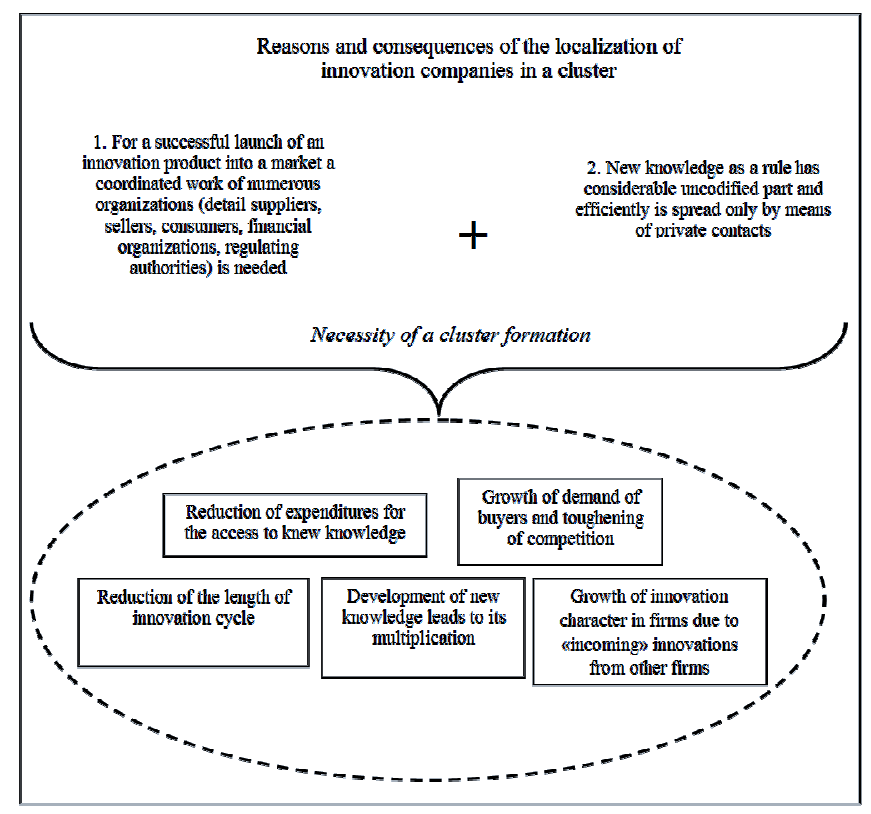

Thus the firms which are interested in an innovation development have all the reasons to focus in specialized clusters. In this respect the problem of the cluster identification becomes important. The method of the analysis of significant cluster groups in the USA and European countries suggested by $M$. Porter is widely used [12]. Its essence consists in the isolation of the employment of so called cluster groups.

D.A. Vuylov suggests evaluating the cluster potential of a regional economic system on the basis of the theory of factors of production which includes accounting of the "factors of possibility of the formation of the cluster potential" and "factors of preparedness of the cluster potential use" [13].

The authors suggest taking as the basis not the number of the employed, not the possibility and capacity for the creation of a cluster potential (although it is important) but the innovation constituent of the cluster potential as the basis of the cluster which can be expressed as a system of indices. In particular the equation for the calculation of the «Coefficient of a localized innovation» on the basis of the availability of innovation objects is suggested.

The given equation reflects only one of many numerous parameters of the evaluation of the innovative cluster potential in the regional economy (innovation objects). Similarly the indices of the presence of innovation goods, number of sold patents, innovation character of the equipment, number of inventions and so on can be used.

The main indices of the importance of an innovation of cluster groups are shown below [11]

$L Q$ - «Coefficient of localized innovation»

Empig - number of innovation objects in the industry ${ }^{i}$ in the $L Q=\underbrace{\frac{E m p_{i g}}{E m p_{g}}} / \frac{E m p_{i}}{E m p}$ region 9

$E m p_{g}$ - total number of innovation objects in the region $g$

$E m p_{i}$ - number of innovation objects in industry ${ }^{i}$

Emp - total number of innovation objects

Size - «Size» of innovation in a cluster group $^{i}$

Empig - number of innovation Size $=\frac{E m p_{i g}}{E m p_{i}}$ objects in a cluster group ${ }^{i}$ in region $g$

Emp $p_{i}$ - number of innovation objects in a cluster group ${ }^{i}$

Facus - «Focus» of innovation cluster group ${ }^{i}$

$$
\text { Facus }=\frac{E m p_{i g}}{E m p_{g}}
$$

Empig - number of innovation objects in a cluster group ${ }^{i}$ in region $g$

Emp $_{g}$ - number of innovation objects in a region 9

A wide spread of approaches and foundations of the qualitative assessment of the cluster potential of a regional economy attracts attention of scientists. Some suggestions raise doubts like the idea of Yu.N. Tomashevskaya to use for the assessment the sociological method of a "snow ball" as in the opinion of the author the research "upon recommendation" will allow removing barriers on the way of getting the information [14]. The doubts are connected with a high share of a subjective factor in the assessment of the objective processes.

In this respect we can agree with the opinion of V.O. Moseyko and V.V. Fesenko that the "complex of parameters should include the indicator both dynamic and also of large scale (static) character and only their simultaneously high 
values for a specific industry of a region can indentify it as the basis of an eventual cluster within the given region" [15].

The rank which a region has in comparison with other regions of Russia (in the rating) which are the producers of the goods of this industry can be taken as an indicator of a large scale development of a specific industry in the given region. In the paper it is suggested to analyze the relative growth of the production of a specific industry as an indicator of the dynamic character.

The given rating $(R)$ is a calculated ratio and it is suggested calculating it using the formula [15].

$$
R=\frac{(N+1)-n}{N} 100 \%
$$

where $N$ - number of the regions being the main producers of the goods of the given industry in Russia;

$n$ - rank of a specific region among the regions which are the main producers of the goods from this industry.

where $\mathbb{I}_{\mathrm{sp}}$ - average regional growth of the production of a specific good per year in the regions which are its main producers in the Russian Federation;

$\Pi_{\mathrm{F}}$ - total increment of the $A=\Pi_{B O} / \Pi_{C P}$ production of a specific production per year in all the regions which are its main producers in Russia or in other words the growth of the production of specific production per year in the whole country;

$N$ - number of the regions which are the main producers of the goods of the given industry in the Russian Federation;

$\Pi_{\mathrm{BO}}$ - regional growth of the production of specific goods per year in a region.

The mentioned approach which develops the idea of employment in the so called cluster groups implemented in the the European countries emphasizes the attention of the production of goods. But similarly it is possible to use the mentioned methodological approach for the evaluation of a new innovation potential of the regional economic system by means of the use of the index of «innovation production».

The indices of share of innovation production and quantitative characteristics of the closeness of relations between the enterprises of an eventual cluster can be used.
These indices even more than employment and production reflect the cluster potential of the regional economy as the availability of technologically interrelated and complementary enterprises in a geographically related territory and their innovation focus are the main attributes of clusters and their qualitative criteria. Even when the assessment of the cluster potential of the regional economy should include the parameters of four basic characteristics of cluster groups (number of employed in cluster groups, volume of produced goods, share of innovation production, share of the goods supplied to one another and the services inside cluster groups) on the basis of the aggregating of these particular indices.

Thus the following conclusions can be made: quantitative assessment of a cluster potential should be multifactorial, integrated, carried out on the basis of a system of indicators determined by qualitative attributes. The main evaluative indicators are the number of employed and the volume of produced goods in potential cluster groups, share of innovation goods and services in the total volume of the produced goods, quantitative characteristic of integration relations of the economic agents of a potential cluster. The innovation activity leads to the reduction of the costs of the access to new knowledge (they have considerable personified part) and leads to the creation of novelties (distribution of new knowledge leads to its multiplication), to the reduction of the length of an innovation cycle, to the activating of innovation activity of firms at the expense of the "incoming" innovations from other companies, to the growth of requirements of buyers and to the strengthening of competitive fight.

As long as the cluster initiative is being introduced, the creation of the conditions for the development and the interaction of the constituents of the mechanisms of cluster formation are becoming more and more important. In this mechanism all the basic elements (competition, market institutes, cluster policy, state and private partnership) should be closely interrelated. The competition will provide the creation and the development of market institutes, serves as a driver of state and private partnership and it is a powerful stimulus of the development of an economic policy. The market institutes, their quality influence directly the development of competition and the regional competitiveness, efficiency of state and private partnership. The state and private partnership is one of the dominants of competition, market institutes and state cluster policy. The state cluster policy in its turn contributes to the increase of competitiveness of all economic agents of a potential cluster, influences the quality of market institutes and serves as one of the bases of state and private partnership.

\section{CONCLUSION}

The use of operational and factor approaches to the identification of cluster potential of a localized territory, of the methodology of cluster analysis allowed drawing the conclusion that the specification of a cluster potential of the regional economy can be implemented on the basis of the analysis of cluster attributes: capability of self organization; territorial localization; capability of efficient use of internal resources; internal competition; competitiveness. The main 
and the most important qualitative attribute of a potential cluster is the innovation focus of its participants.

It is suggested to calculate the quantitative characteristics by means of the analysis of the importance of the innovations obtained in cluster groups on the basis of the calculation of the «Coefficient of a localized innovation». The authors suggest taking as a basis not the number of the employed and not the possibility and capability of the creation of the cluster potential (although it is important) but an innovation component of the cluster potential which can be expressed by the system of indices. The elements of the mechanism of the encouragement of innovation cluster initiative are as follows: competition, market institutes, cluster policy, state and private partnership.

The formation of clusters in the countries with the developed market economy is the reflection of the objective process of the globalization and the strengthening of competitive fight in the world economy. Under the conditions of an open economy this all generates a need for a sharp increase of the competitiveness of various Russian firms from small, medium sized to large scale business what under modern conditions can be achieved only together with the growth of competitiveness of closely related, geographically closely located innovation enterprises, scientific and educational organizations (i.e. clusters).

As the cluster initiative develops it becomes more and more important to create the conditions for the appearance and for the interaction of the elements of the mechanism of cluster formation. In this mechanism all the basic elements (competition, market institutes, cluster policy, state and private partnership) should be closely interrelated. In this respect the problem of cluster identification, specification of the cluster potential of localized territory becomes relevant. This situation implies the activation of the research of the functioning of a complicated economic system like a cluster. The prospects of the use of this sphere of research are determined by a complicated process of the cluster formation in the Russian economy which is now at initial stage and also by the Russian specificity of formation and development of clusters.

\section{References}

[1] Inshakov O.V. "Yadro razvitiya" v kontekste novoi teorii faktorov proizvodstva ["Nucleus of develompent" in the context of new theory of factors of production]. Ekonomicheskaya nauka sovremennoi Rossii [Economic science of contemporary Russia], 2003, № 1, pp. 11-25.
[2] Frolov D.P., Grushevskiy D.V. Institutsional'no-ekonomicheskaya priroda klasterov [Institutional and economic nature of clusters]. Ekonomika regiona [Economy of a region], 2008, № 2, pp. 230-234.

[3] Porter M.E. Ekonomicheskoe razvitie regionov [Economic development of regions]. Prostranstvennaya ekonomika [Spatial economy], 2007, № 1, p. 109.

[4] Raevskaya E.A. Klastery kak raznovidnost' setevoi struktury [Clusters as a type of net structure]. Voprosy novoi ekonomiki [Problems of new economy], 2012, № 3, p. 15.

[5] Ferova I.S. Klasternye printsipy organizatsii proizvodstvennogo vzaimodeistviya [Cluster principles of the organization of production interaction]. Ekonomicheskie problemy i resheniya [Economic problems and solutions], 2004, № 2, p. 53.

[6] Peeters L., Tiri M., Berwert A. Techno-economic Clusters in Flanders and Switzerland: an Input-Output-Analysis. Center for Science and Technology Studies (CEST), № 9, July 2001, P. 7.

[7] Polanyi K. Personal Knowledge: Towards a Post-Critical Philosophy. Chicago: University of Chicago Press, 1958.

[8] Desrochers P. Geographical Proximity and the Transmission of Tacit Knowledge. Review of Austrian Economics, 2001, Vol. 14, № 1. P. 25 46. Available at: www.gmu.edu/rae/archives / V0L14_1_2001/2_desrochers.pdf. Reference date 15.01.2018.

[9] Pyat' vzglyadov na strategiyu dostizheniya liderstva na rynke. Po materialam knigi D. G. Boietta i D. T. Boietta «Putevoditel' po tsarstvu mudrosti. Luchshie idei masterov upravleniya» [Five opinions on the strategy of leadership in a market. On the basis of the book by D.G. Boyett and D.T. Boyett "Guide in wisdom kingship. Best ideas from the baster of managers]. Available at: www.altrc.ru/media/File/Articles /1PDF-versions/5\%20P.pdf. p. 21. Reference date 15.01.2018.

[10] Biznes -angely v Rossii i za rubezhom [Business angels in Russia and abroad]. Available at: www.techbusiness.ru/ content/?lang $=$ ru\&div $=47$. Reference date 15.01.2018.

[11] Kutsenko E., Tyumentseva D. Klastery i innovatsii v sub"ektakh RF: rezul'taty empiricheskogo issledovaniya [Clusters and innovations in the regions of Russia: results of empirical reserch]. Voprosy ekonomiki [Problems of economy], 2011, № 9, p. 98.

[12] Porter M. The Economic Performance of Regions. Regional Studies, 2003, Vol. 37, № 6-7, P. 549-578.

[13] Vuylov D.A. Formirovanie i razvitie klasternykh obrazovanii na territorii regiona: Avtoref. dis. ... kand. ekon. Nauk [Formation and development of clusters in the territory of a region: Synopsis of the thesis of the candidate of economic sciences]. Volgograd, 2011, pp. 1718.

[14] Tomashevskaya Yu. N. Teoreticheskie i metodicheskie osnovy identifikatsii klasterov v ekonomike rossiiskikh regionov: Avtoref. dis. ... kand.ekon.nauk [Theoretical and methodic bases of the identification of clusters in the economy of Russian regions: Synopsis of the thesis of the candidate of economic sciences], Astrakhan, 2012, p. 20.

[15] Moseyko V.O., Fesenko V.V. Vyyavlenie regional'nykh klasterov: metodologicheskie podkhody [Isolation of regional clusters: methodological approaches]. Regional'naya ekonomika: teoriya i praktika [Regional economics: theory and practice], 2008, № 7, p. 60 . 